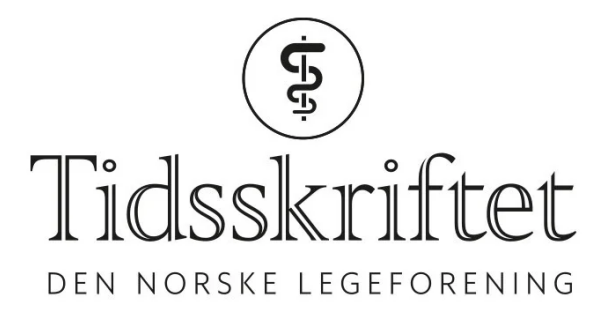

\title{
Ingen effekt av antibiotika ved korsryggssmerter
}

FRA ANDRE TIDSSKRIFTER

SOFIE PAUS

Tidsskriftet

Tre måneders behandling med amoksicillin ga ingen bedring hos pasienter med korsryggssmerter og Modicforandringer.

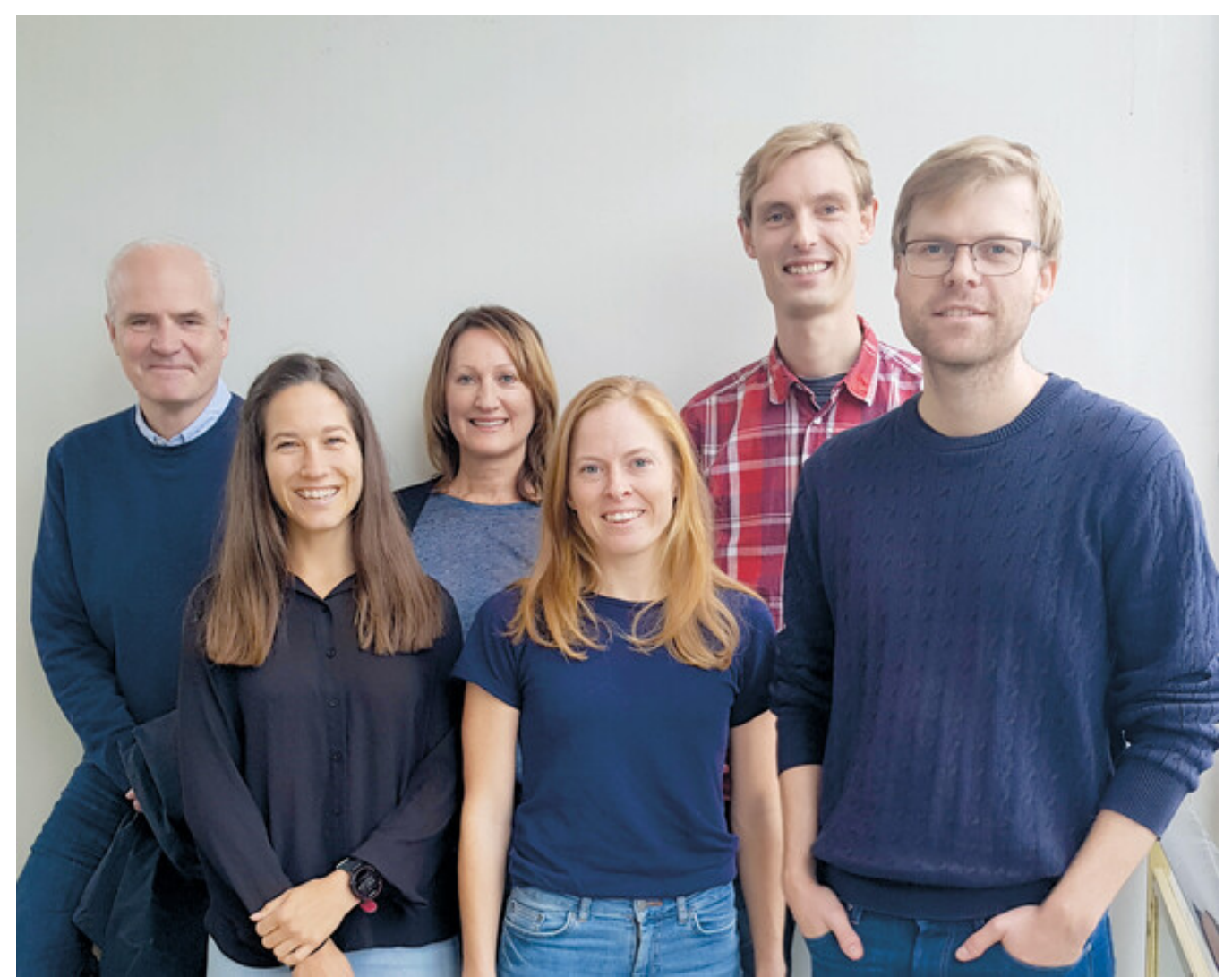

Forfatterne av studien. Fra venstre: John-Anker Zwart, Maria Dehli Vigeland, Kjersti Storheim, Monica Wigemyr, Lars Christian Bråten og Mads Peder Rolfsen. Foto: Linda Margreth Pedersen 
Ved MR-undersøkelse kan man hos noen pasienter med langvarige korsryggssmerter se affeksjon av virvelcorporas endeplate, såkalte Modic-forandringer. Slike forandringer deles inn i tre typer, karakterisert av henholdsvis ødem, fett og sklerose. Patogenesen er ikke fullstendig kartlagt, men tilstanden er muligens forårsaket av bakterien Cutibacterium acnes (tidligere kalt Propionibacterium acnes).

I en norsk studie som omfattet 180 pasienter med tidligere skiveprolaps, vedvarende ryggsmerter og Modic-forandringer ved seks sykehus, ble pasientene randomisert til antibiotikabehandling med amoksicillin eller placebo i 100 dager (1). Pasientenes ryggsmerte og funksjonsevne ble vurdert med det validerte spørreskjemaet Roland-Morris Disability Questionnaire (RMDQ).

Etter et år var forskjellen i gjennomsnittlig RMDQ-skår mellom de to gruppene -1,6 (95 \% KI -3,1-0,0) i favør av antibiotika, men den var langt mindre enn den forhåndsdefinerte grensen på 4 for klinisk signifikant forskjell. Lignende funn ble gjort for smerter og livskvalitet. Andelen pasienter med én eller flere legemiddelbivirkninger var henholdsvis $56 \%$ i antibiotikagruppen og $34 \%$ i placebogruppen.

Disse resultatene er ikke i overenstemmelse med en randomisert studie fra Danmark, som viste en markant bedring i RMDQ-skår med antibiotikabehandling (2 2 ).

- Den norske studien ble initiert for å etterprøve resultatene fra den danske studien, sier Lars Christian Haugli Bråten, som var førsteforfatter og nylig disputerte på emnet.

- Våre funn viser at antibiotikabehandling ikke kan anbefales mot langvarige korsryggssmerter hos pasienter med Modic-forandringer, sier han. 


\section{Direct-to-consumer}

\section{genetic testing \\ What to tell patients}

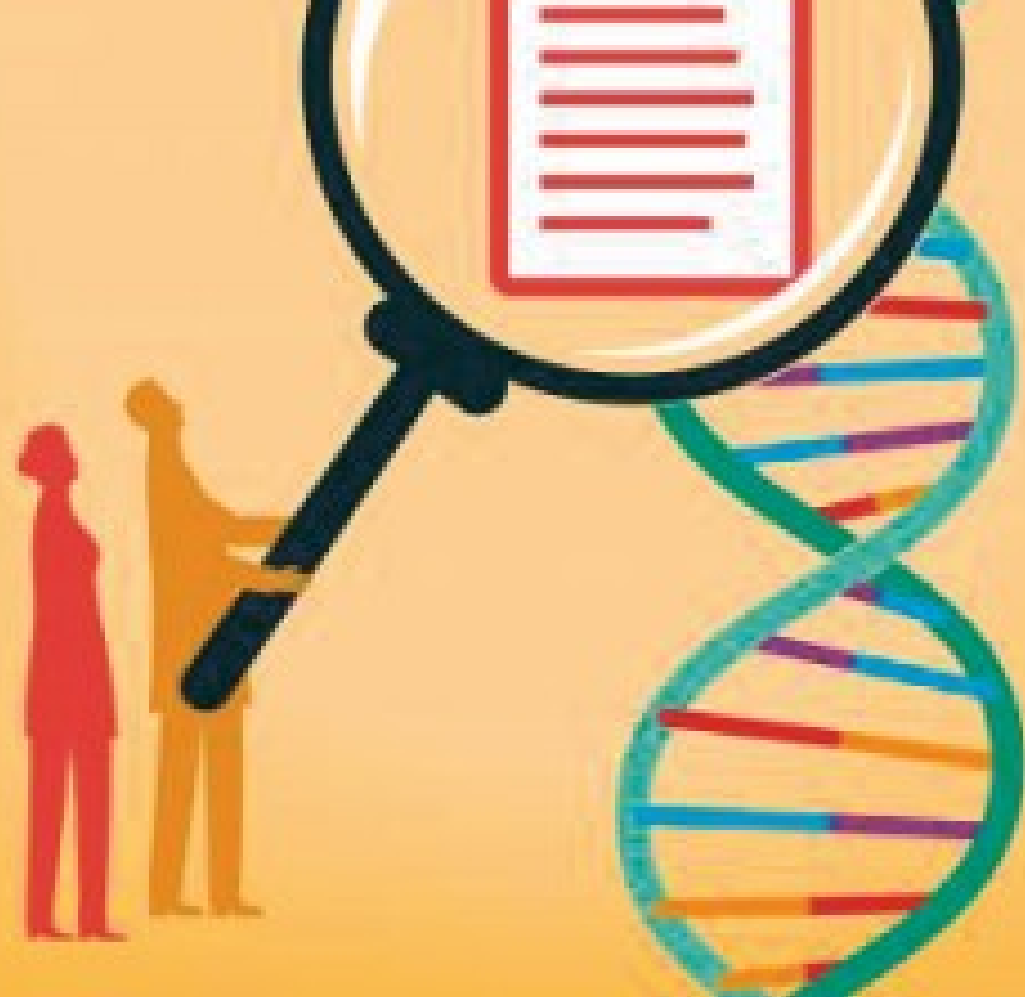

Artikkelen ble publisert i tidsskriftet BMJ i oktober 2019.

Studien utgår fra Forsknings- og formidlingsenheten for muskelskjeletthelse (FORMI) ved Nevroklinikken på Oslo universitetssykehus, Ullevål. Også Universitetssykehuset NordNorge, St. Olavs hospital, Haukeland universitetssjukehus, Drammen sykehus og Sykehuset $\emptyset$ stfold Moss bidro. Fire stipendiater er tilknyttet prosjektet, der Bråten er den første som har disputert.

\section{Forskningsgruppen}

Forsknings- og formidlingsenheten for muskelskjeletthelse utfører kliniske, epidemiologiske, helseøkonomiske, genetiske og basale forskningsprosjekter om sykdommer, skader og plager i muskel og skjelett. Enheten har publisert nasjonale retningslinjer for behandling av ryggsmerter og har publisert en rekke artikler i internasjonalt anerkjente tidsskrifter, slik som JAMA, Nature Genetics og BMJ, og har laget informasjonsvideoer rettet mot pasienter. Forskningsgruppen jobber også med å teste behandlingsformer basert på mulige årsaker til Modic-forandringer. 


\section{LITTERATUR}

1. Bråten LCH, Rolfsen MP, Espeland A et al. Efficacy of antibiotic treatment in patients with chronic low back pain and Modic changes (the AIM study): double blind, randomised, placebo controlled, multicentre trial. BM] 2019;367: 15654. [PubMed][CrossRef]

2. Albert HB, Sorensen JS, Christensen BS et al. Antibiotic treatment in patients with chronic low back pain and vertebral bone edema (Modic type 1 changes): a double-blind randomized clinical controlled trial of efficacy. Eur Spine J 2013; 22: 697-707. [PubMed][CrossRef]

Publisert: 4. mai 2020. Tidsskr Nor Legeforen. DOI:10.4045/tidsskr.20.0193

(C) Tidsskrift for Den norske legeforening 2023. Lastet ned fra tidsskriftet.no 26. april 2023. 